\title{
Addition of Brassica alboglabra Bailey chromosomes to $B$. campestris L. with special emphasis on seed colour
}

\author{
B. F. CHENG*, B. Y. CHEN \& W. K. HENEEN \\ Department of Plant Breeding Research, Swedish University of Agricultural Sciences, S-268 31 Svalöv, Sweden
}

\begin{abstract}
A resynthesized Brassica napus line (AACC, $2 n=38$ ) was successively backcrossed to its parental $B$. campestris (AA, $2 n=20)$ to develop monosomic addition lines that contain the different chromosomes of the other parent $B$. alboglabra (CC, $2 n=18)$. Special emphasis was put on identifying monosomic addition lines with $B$. alboglabra chromosome(s) carrying genes for black seed colour. Four different types of monosomic addition plants were obtained. One of them harboured a $B$. alboglabra chromosome with gene(s) for black seed colour while another type of monosomic addition plant had the B. alboglabra chromosome with the gene for white flower colour. The remaining two carried hitherto unmarked $\mathrm{C}$-genome chromosomes and were distinguished from each other by the morphology of the alien chromosome at diakinesis of meiosis. Meiotic studies revealed that the monosomic addition plants for the white flower colour or black seed colour had a higher trivalent frequency in the pollen mother cells when compared with the two unmarked monosomic addition plants. Two different types of double-monosomic addition plants were also obtained. Such double-monosomic addition plants will be useful to reveal intragenomic homoeology of the B. alboglabra chromosomes.
\end{abstract}

Keywords: addition line, Brassica alboglabra, B. campestris, chromosome homoeology, flower colour, meiosis, seed colour.

\section{Introduction}

U (1935) established the evolutionary origin of three cultivated Brassica amphidiploid species, B. napus L. (AACC, $2 n=38$ ), B. juncea (L.) Czern (AABB, $2 n=36)$ and $B$. carinata $\mathrm{Br}$. (BBCC, $2 n=34)$ as a result of interspecific hybridization between the three diploid species, B. campestris L. (AA, $2 n=20), B$. oleracea L. (CC, $2 n=18)$ and B. nigra (L.) Koch (BB, $2 n=16)$. The phylogenetic relationships of the three diploid A-, B- and C-genomes have been studied at the cytological and molecular levels (Attia \& Röbbelen, 1986; Attia et al., 1987; Tai \& Ikonen, 1988; Song et al., 1988). B. campestris and B. oleracea have a close evolutionary relationship while $B$. nigra is more distantly related.

Recently, the generation and analysis of alien chromosome addition lines has been used as one strategy for dissecting the Brassica genomes. For instance, $B$. campestris- $B$. oleracea, Diplotaxiserucoides- $B$. nigra and $B$. napus- $B$. nigra monosomic addition lines have been

\footnotetext{
${ }^{*}$ Correspondence.
}

successfully developed (Quiros et al., 1987; Jahier et al., 1989; McGrath \& Quiros, 1990; Struss et al., 1991; Chen et al., 1992). The addition lines have proved to be useful in identifying gene linkage groups and investigating chromosome homoeology within and between genomes in Brassica (This et al., 1990; Chevre et al., 1991; Chen et al., 1992). This approach has also been successfully used in transferring agronomic traits between species. The substitution of a B-genome chromosome in $B$. juncea by its $\mathrm{C}$-genome homoeologue from $B$. napus gives rise to variation for erucic acid content and bolting habit (Banga, 1988). The introgression of genes from the $\mathrm{C}$ - to the A-genome has also been detected in B. campestris-oleracea/alboglabra addition lines (Quiros et al., 1987; Chen et al., 1992).

Seed colour is an important agronomic trait in Brassi$c a$ because it is related to the oil, protein and fibre contents of the seed (Chen \& Heneen, 1992). In order to characterize $B$. alboglabra (a form of $B$. oleracea) chromosome(s) with genes for black seed colour, we have dissected the $B$. alboglabra genome by generating addition lines from resynthesized $B$. napus. The Indian $B$. campestris yellow sarson $\mathrm{K}-151$ is a stable and pure 
yellow-seeded breeding line. The black seed colour of $B$. alboglabra accession no. 4003, however, is dominant over the yellow seed colour of $\mathrm{K}-151$ in the resynthesized B. napus line no. 7406 (Chen \& Heneen, 1992). Thus, the black-seeded phenotype of a $B$. campestris-alboglabra monosomic addition line $(2 n=21)$ in a background of K-151 would indicate a $B$. alboglabra chromosome with gene(s) for black seed colour. The present paper is concerned with the addition of $B$. alboglabra chromosomes to K-151 with special emphasis on the seed colour trait.

\section{Materials and methods}

Resynthesized B. napus line no. 7406 was produced from a cross between $B$. campestris var. yellow sarson accession K-151 and B. alboglabra accession no. 4003 (Chen et al., 1988, 1989). The K-151 line was yellowflowered and yellow-seeded whereas no. 4003 was white-flowered and black-seeded. Therefore, the white flower and black seed colour of the resynthesized $B$. napus line no. 7406 were due to the expression of dominant genes, controlling these two traits, on the $B$. alboglabra chromosomes. B. napus no. 7406 , used as female parent, was crossed with parental $B$. campestris $\mathrm{K}-151$ to produce a trigenomic hybrid (AAC, $2 n=29$ ). The seeds obtained after selfing and backcrossing the trigenomic hybrid to $\mathrm{K}-151$ were pooled as the $\mathrm{BC}_{1}$ aneuploid progeny. The $\mathrm{BC}_{1}$ aneuploid plants were scored for flower colour, seed colour and chromosome number.

One white-flowered and black-seeded $\mathrm{BC}_{1}$ aneuploid plant with four $B$. alboglabra chromosomes $(2 n=24)$ was further backcrossed to the parental $B$. campestris $\mathrm{K}-151$ to produce $\mathrm{BC}_{2}$ seeds. The resulting $\mathrm{BC}_{2}$ plants were studied for flower colour, seed colour and chromosome number in a search for monosomic addition plants harbouring $B$. alboglabra chromosomes with genes for black seed colour.

For meiotic analyses, fixation in Farmer's solution and staining in Snow's carmine were as reported by Chen et al. (1992). The chromosome number of each plant was determined by studying more than 20 pollen mother cells (PMCs) at metaphase I/anaphase I. The $\chi^{2}$ test was performed to confirm the independent transmission of the white flower and black seed colour traits in the $\mathrm{BC}_{2}$ progeny.

\section{Results}

Crossability of resynthesized $B$. napus no. 7406 and the trigenomic hybrid ( $A A C, 2 \mathrm{n}=29)$ with $\mathrm{B}$. campestris $K-151$

On average, four seeds per silique (range 2-9) were obtained in the crosses between B. napus no. 7046
(AACC, $2 n=38$ ) and B. campestris $\mathrm{K}-151$ (AA, $2 n=20$ ). The resulting trigenomic hybrid (AAC, $2 n=29$ ) was further backcrossed to K-151 to produce aneuploid seeds. On average, two seeds per silique(range 0.3-4) were obtained in these backcrosses. Compared with the seed-setting in the parental species no. 7406 (11-18 seeds/silique) and K-151 (16-27 seeds/silique), the crossability of no. 7406 and the trigenomic hybrid with K-151 was low. Selfing of the trigenomic hybrid also produced aneuploid seeds. The aneuploid seeds from these two sources, referred to as the $\mathrm{BC}_{1}$ aneuploid progeny, were used for generating alien chromosome addition lines.

\section{Segregation of flower colour and seed colour in the $B C_{1}$ and $B C_{2}$ aneuploid progeny}

In the $\mathrm{BC}_{1}$ aneuploid progeny, 90 plants were recorded for flower colour. Eighty-eight plants were whiteflowered, and the remaining two plants yellow. Thirtyfive plants set seeds and were checked for seed colour. Thirty-four plants produced black seeds while only one plant had yellow seeds.

The $\mathrm{BC}_{2}$ progeny from a white-flowered and blackseeded $\mathrm{BC}_{1}$ aneuploid plant with $2 n=24$ was used to screen for monosomic addition lines. Forty-nine $\mathrm{BC}_{2}$ plants were recorded for flower colour and seed colour (Table 1). Seventeen plants ( 34.7 per cent) showed white flowers and the remaining 32 plants yellow flowers. Eighteen plants ( 36.7 per cent) gave rise to black seeds whereas the other 31 plants produced yellow seeds. The joint segregation of these two characters fits with the assumption of independent transmission (Table 1).

\section{Distribution of the alien chromosomes in the $B C_{2}$ progeny}

In this $\mathrm{BC}_{2}$ progeny, chromosome number was determined in 22 plants and varied from $2 n=20$ to $2 n=24$ (Table 2).

Two progeny plants were diploid $(2 n=20)$ with yellow flowers and yellow seed colour and thus were the parental B. campestris type (Table 2). Four of the seven monosomic addition plants $(2 n=21)$ obtained were white-flowered and yellow-seeded. Evidently, the chromosome with the gene for white flower colour from the C-genome was present in these plants. One monosomic addition plant was yellow-flowered and blackseeded, thus containing an alien chromosome with gene(s) for black seed colour. The other two monosomic addition plants, with yellow flowers and yellow seed colour, carried unmarked C-genome chromosomes. However, these two plants could be differentiated by the morphology of the alien chromosome in PMCs at diakinesis of meiosis. The alien chromosome in one plant 
Table 1 Joint segregation of flower colour and seed colour in the $\mathrm{BC}_{2}$ progeny derived from a $\mathrm{BC}_{1}$ aneuploid plant with $2 n=24$ chromosomes. Expectation is based on independent transmission

\begin{tabular}{lllccc}
\hline \multicolumn{2}{c}{ Character } & & \multicolumn{3}{c}{ No. of plants } \\
\cline { 1 - 3 } $\begin{array}{l}\text { Flower } \\
\text { colour }\end{array}$ & $\begin{array}{c}\text { Seed } \\
\text { colour }\end{array}$ & & \multicolumn{2}{c}{ Observed } & Expected \\
& & & $\%$ & No. \\
\hline White & Black & & 5 & 10.2 & 6.2 \\
& Yellow & & 12 & 24.5 & 10.8 \\
Yellow & Black & & 13 & 26.5 & 11.8 \\
& Yellow & & 19 & 38.8 & 20.2 \\
& $\chi^{2}=0.56$ & d.f. $=1$ & & $P=0.30-0.50$ \\
\hline
\end{tabular}

Table 2 Genetic trait and chromosome number combinations in the $\mathrm{BC}_{2}$ progeny derived from a $\mathrm{BC}_{1}$ aneuploid plant with $2 n=24$ chromosomes

\begin{tabular}{|c|c|c|c|c|c|c|}
\hline \multicolumn{2}{|c|}{ Trait } & \multirow{2}{*}{\multicolumn{5}{|c|}{ Chromosome number $(2 n)$}} \\
\hline \multirow{2}{*}{$\begin{array}{l}\text { Flower } \\
\text { colour }\end{array}$} & \multirow{2}{*}{$\begin{array}{l}\text { Seed } \\
\text { colour }\end{array}$} & & & & & \\
\hline & & 20 & 21 & 22 & 23 & 24 \\
\hline \multirow[t]{2}{*}{ White* } & Black* & & & & 1 & 1 \\
\hline & Yellow & & 4 & & 2 & \\
\hline \multirow[t]{2}{*}{ Yellow } & Black* & & 1 & 1 & 4 & \\
\hline & Yellow & 2 & 2 & 4 & & \\
\hline Total & & 2 & 7 & 5 & 7 & 1 \\
\hline
\end{tabular}

*Traits controlled by the C-genome chromosomes.

was always stained darkly in the middle pericentric region and lightly in the distal parts of the two arms (arrow,Fig. 1a). The other alien chromosome was stained darkly in one arm and lightly in the other (arrow, Fig. 1b).

One of the five double-monosomic addition plants $(2 n=22)$ obtained was yellow-flowered and blackseeded. Thus, it contained the alien chromosome with gene(s) for black seed colour and one of the two unmarked alien chromosomes. The remaining four were yellow-flowered and yellow-seeded and thus carried the same two hitherto unmarked C-genome chromosomes.

\section{Meiosis of monosomic and double-monosomic addition lines}

Chromosomal configurations in PMCs at diakinesis or first metaphase were investigated in the monosomic and double-monosomic addition plants (Table 3). The frequency of trivalents was much higher in the whiteflowered and black-seeded monosomic addition plants compared with the two types of unmarked addition plants.

In the yellow-flowered and black-seeded doublemonosomic addition plant, the two alien chromosomes were univalents (arrow, Fig. 1c) in 77.4 per cent of PMCs whereas a trivalent and a univalent were observed in the remaining 22.6 per cent of PMCs (Table 3). In the unmarked double-monosomic addition plant, the two alien chromosomes were univalents in 96.8 per cent of PMCs.

\section{Discussion}

The independent transmission of white flower and black seed traits in the $\mathrm{BC}_{2}$ aneuploid progeny (Table 1) may imply that the genes controlling these two traits are located on separate $B$. alboglabra chromosomes. This is further verified by development of the two types of monosomic addition plants, with white flower and black seed, respectively (Table 2 ).

Chen \& Heneen (1992) reported that the black seed colour in B. alboglabra was governed by two independent dominant genes with duplicated effect. If these two independent genes are not located on the same $B$. alboglabra chromosome, we should be able to develop two different types of black-seeded $B$. campestrisalboglabra monosomic addition lines. Only one has been developed so far. Further dissection of the B. alboglabra genome in a yellow sarson $\mathrm{K}-151$ background might lead to the generation of the other black-seeded B. campestrisalboglabra monosomic addition line.

The transmission of $B$. alboglabra chromosomes varied in different backcross generations, as indicated by the marker traits. The transmission rate of the white flower character decreased from 97.8 per cent in the $\mathrm{BC}_{1}$ generation to 34.7 per cent in the $\mathrm{BC}_{2}$ progeny. The transmission of a $B$. oleracea isozyme marker Pgm- 1 also varied between different backcrossed generations (McGrath \& Quiros, 1990). There may be several reasons for this. Gamete selection might have some impact on the transmission of the alien chromosome (McGrath \& Quiros, 1990). Pairing among chromosomes of the $\mathrm{C}$-genome in a $B$. campestris background may also affect the transmission of alien chromosomes between generations. For example, in the trigenomic hybrid plant $(\mathrm{AAC})$, the C-genome chromosome carrying the gene for white flower colour might pair with its intragenomic homoeologues to form a bivalent, or pair with A-genome homoeologues to form a trivalent, while in the aneuploid plant with four B. alboglabra chromosomes $(2 n=24)$, the C-genome chromosome carrying the gene for white flower colour might only pair with A-genome homoeologues to form a trivalent. The lack of intragenomic homoeologous pairing in the aneuploid plant $(2 n=24)$ might thus contribute to the reduction in 


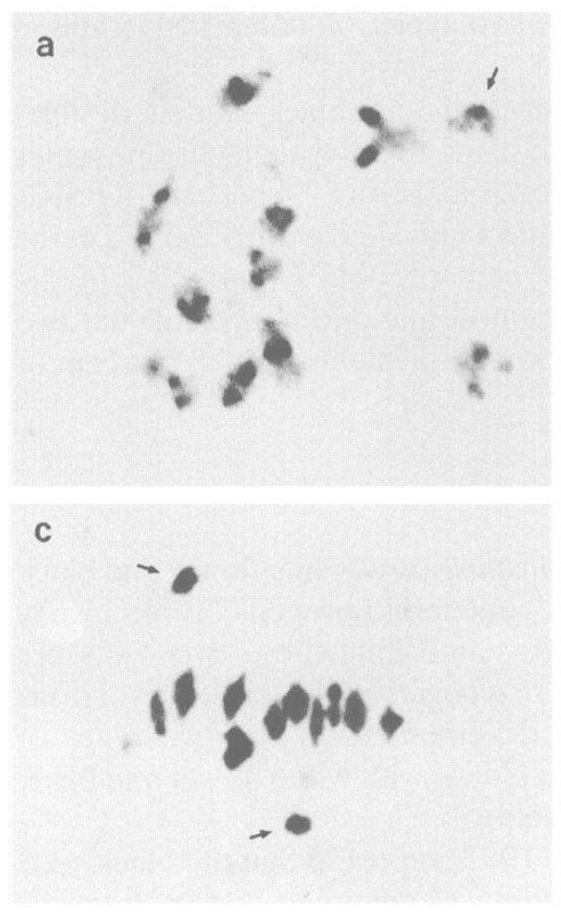

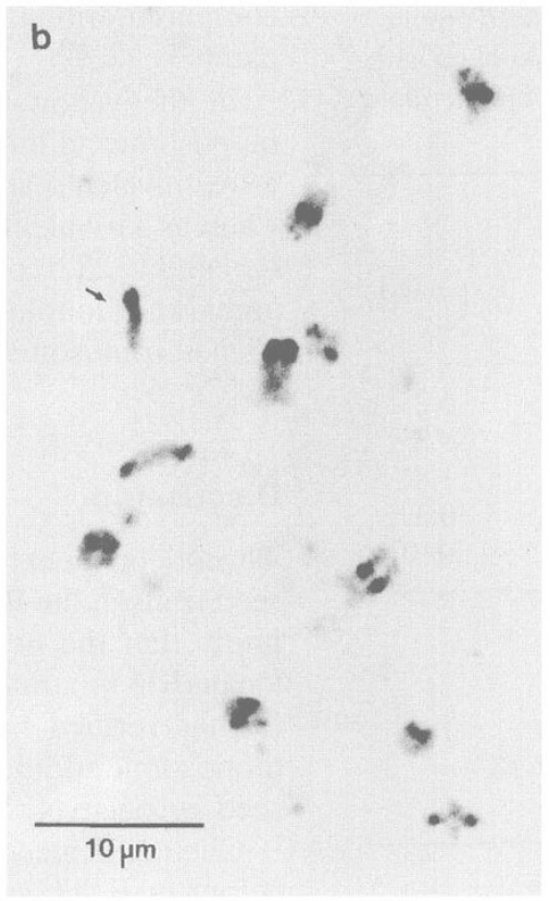

Fig. 1 Chromosome configurations at diakinesis or first metaphase (MI) of meiosis in the two unmarked $B$. campestris-alboglabra monosomic addition lines and in one double monosomic addition line. (a) 10 II + 1 I (arrow), the alien univalent stained darkly in the middle pericentric region and lightly in the distal parts of the two arms. (b) $10 \mathrm{II}+1 \mathrm{I}$ (arrow), the alien univalent stained darkly in one arm and lightly in the other arm. (c) MI of one double monosomic addition line showing $10 \mathrm{II}+2 \mathrm{I}$ (arrows).

Table 3 Chromosome pairing in pollen mother cells (PMCs) at diakinesis or first metaphase of meiosis in Brassica campestris-alboglabra monosomic $(2 n=21)$ and double monosomic $(2 n=22)$ alien chromosome addition plants

\begin{tabular}{|c|c|c|c|c|c|}
\hline \multirow[b]{3}{*}{ Addition plants } & \multirow{3}{*}{$\begin{array}{c}\text { No. of PMCs } \\
\text { observed }\end{array}$} & \multicolumn{4}{|c|}{ Chromosome configuration } \\
\hline & & \multicolumn{2}{|c|}{$10 \mathrm{II}+1 \mathrm{I}$} & \multicolumn{2}{|c|}{$1 \mathrm{III}+9 \mathrm{II}$} \\
\hline & & PMCs & $\%$ & PMCs & $\%$ \\
\hline \multicolumn{6}{|l|}{ Monosomics } \\
\hline White flower $\dagger$ & 94 & 57 & 60.6 & 37 & 39.4 \\
\hline Black seed & 33 & 19 & 57.6 & 14 & 42.4 \\
\hline Unmarked (Fig. 1a) & 50 & 47 & 94.0 & 3 & 6.0 \\
\hline \multirow[t]{3}{*}{ Unmarked (Fig. 1b) } & 12 & 12 & 100.0 & & \\
\hline & & \multicolumn{2}{|c|}{$10 \mathrm{II}+2 \mathrm{I}$} & \multicolumn{2}{|c|}{$1 \mathrm{III}+9 \mathrm{II}+1$} \\
\hline & & PMCs & $\%$ & PMCs & $\%$ \\
\hline \multicolumn{6}{|l|}{ Double monosomics } \\
\hline Black seed & 31 & 24 & 77.4 & 7 & 22.6 \\
\hline Unmarked & 95 & 92 & 96.8 & 3 & 3.2 \\
\hline
\end{tabular}

†Chromosome configurations studied at diakinesis only.

transmission of the C-genome chromosome with the gene for white flower colour.

The C-genome chromosome may have different degrees of homoeology with the A-genome chromosomes. In the two white-flowered and black-seeded monosomic addition plants, the trivalent frequencies are much higher than in the two unmarked addition plants (Table 3), suggesting that the former have a higher degree of homoeology with the A-genome chromosomes than the latter. That the extent of homoeology, and consequently pairing, between chromosomes of different genomes is a consequence of structural differences or 
similarities is nicely demonstrated for chromosome 4A in wheat (Naranjo et al., 1988; Gill et al., 1991).

In the unmarked double-monosomic addition plant, the two alien chromosomes did not pair with each other (Table 3), indicating apparent lack of intragenomic homoeology between the two alien $\mathrm{C}$-genome chromosomes. Generation of different combinations of doublemonosomic addition lines would help to elucidate the secondary polyploid nature of the $B$. alboglabra genome.

\section{Acknowledgements}

The authors thank Dr Mats Gustafsson and Carita Lannér-Herrera for their comments on the manuscript and Kerstin Brismar for preparing the figures. This work was supported by the Scandinavian Contact Agency for Agricultural Research (The Swedish Research Council for Agriculture and Forestry), Hilleshög $A B$ and the Foundation of Swedish Oilseed Research/The Association of Swedish Seed and Oilseed Growers.

\section{References}

ATTIA, T. AND RÖBBELEN, G. 1986. Cytogenetic relationship within cultivated Brassica analysed in amphihaploids from the three diploid ancestors. Can. J. Genet. Cytol., 28, 323-329.

ATTIA, T., BUSSo, C. AND RÖBBELEN, G. 1987. Digenomic triploids for an assessment of chromosome relationships in the cultivated diploid Brassica species. Genome, 29, 326-330.

BANGA, s. s. 1988. C-genome chromosome substitution lines in Brassica juncea (L.) Coss. Genetica, 77, 81-84.

CHEN, B. Y. AND HENEEN, W. K. 1992. Inheritance of seed colour in Brassica campestris L. and breeding for yellow-seeded $B$. napus L. Euphytica, 59, 157-163.

CHEN, B. Y., HENEEN, W. K. AND JÖNSSON, R. 1988. Resynthesis of Brassica napus L. through interspecific hybridization between $B$. alboglabra Bailey and $B$. campestris L. with special emphasis on seed colour. Plant Breed., 101, 52-59. CHEN. B. Y., HENEEN, W. K. AND SIMONSEN, v. 1989. Comparative and genetic studies of isozymes in resynthesized and cultivated Brassica napus L., B. campestris L. and B, alboglabra Bailey. Theor. Appl. Genet., 77, 673-679.

CHEN, B. Y., SIMONSEN, Y., LANNER-HERRERA, C. AND HENEEN, W. K. 1992. A Brassica campestris-alboglabra addition line and its use for gene mapping, intergenomic gene transfer and generation of trisomics. Theor. Appl. Genet., 84, 592-599. CHEVRE, A. M., THIS, P., EBER, F., DESCHAMPS, M., RENARD, M., DELSENY, M. AND QUIROS, C. F. 1991. Characterization of disomic addition lines of Brassica napus-Brassica nigra by isozyme, fatty acid, and RFLP markers. Theor. Appl. Genet., 81, 43-49.

GILL, B. S., FRIEBE, B. AND ENDO, T. R. 1991. Standard karyotype and nomenclature system for description of chromosome bands and structural aberrations in wheat (Triticum aestivum). Genome, 34, 830-839.

JAHIER, J., CHEVRE, A. M., TANGUY, A. M. AND EBER, F. 1989. Extraction of disomic addition lines of Brassica napus- $B$. nigra. Genome, 32, 408-413.

MCGRATH, J. M. AND QUIROS, C. F. 1990. Generation of alien chromosome addition lines from synthetic Brassica napus: morphology, cytology, fertility, and chromosome transmission. Genome, 33, 374-383.

NARANJo, T., ROCA, A., GOICOECHEA, P. G. AND GIRALDEZ, R. 1988. Chromosome structure of common wheat: Genome reassignment of chromosomes $4 \mathrm{~A}$ and $4 \mathrm{~B}$. In: T. E. Miller and R. M. D. Koebner (eds) Seventh International Wheat Genetics Symposium, vol. 1, pp. 115-120. Institute of Plant Science Research, Cambridge Laboratory, Cambridge, U.K.

QUIROS, C. F., OCHOA, O., KIANIAN, S. F. AND DOUCHES, D. 1987. Analysis of the Brassica oleracea genome by the generation of $B$. campestris-oleracea chromosome addition lines: characterization by isozymes and rDNA genes. Theor. Appl. Genet., 74, 758-766.

SONG, K. M., OSBORN, T. C. AND WILliAMS, P. H. 1988. Brassica taxonomy based on nuclear restriction fragment length polymorphisms (RFLPs). I. Genome evolution of diploid and amphidiploid species. Theor. Appl. Genet., 75, 784-794.

STRUSS, D., BELLIN, U. AND RÖBBELEN, G. 1991. Development of B-genome chromosome addition lines of $B$. napus using different interspecific Brassica hybrids. Plant Breed., 106, 209-214.

TAI, W. AND IKONEN, H. 1988. Incomplete bivalent pairing in dihaploids of Brassica napus L. Genome, 30, 450-457.

THIS, P., OCHOA, O. AND QUIROS, C. F. 1990. Dissection of the Brassica nigra genome by monosomic addition lines. Plant Breed., 105, 211-220.

U, N. 1935. Genome-analysis in Brassica with special reference to the experimental formation of $B$. napus and peculiar mode of fertilization. Jap. J. Bot., 7, 389-452. 